\title{
FACTORS ASSOCIATED WITH EARLY INITIATION OF BREASTFEEDING AMONG MOTHERS OF DIBRUGARH DISTRICT, ASSAM- A COMMUNITY-BASED CROSS-SECTIONAL STUDY
}

\author{
Rahul Kumar Sarmahㄹ, Ratna Sarma², Hiranya Saikia ${ }^{3}$ \\ 1 Postgraduate Trainee, Department of Community Medicine, Assam Medical College, Dibrugarh, Assam. \\ 2 Professor and HOD, Department of Community Medicine, Assam Medical College, Dibrugarh, Assam. \\ ${ }^{3}$ Senior Lecturer (Non-Medical) Biostatistics, Department of Community Medicine, Assam Medical College, Dibrugarh, Assam.
}

\section{ABSTRACT}

\section{BACKGROUND}

Early or timely initiation of breastfeeding, specifically within 1 hour of birth, refers to the best practice recommended by the World Health Organization (WHO). There is growing evidence of the significant impact of early initiation of breastfeeding, preferably within the first hour after birth, on reducing overall neonatal mortality. The present study has been undertaken with an objective to study the current prevalence of early initiation of breastfeeding in Dibrugarh district, Assam, India and to assess the various factors influencing early initiation of breastfeeding.

\section{MATERIALS AND METHODS}

The present study was a community-based cross-sectional study conducted among 354 mothers having children up to 1 year of age from June 2015 to May 2016. Multistage sampling was used to select mothers for the study. A pre-designed and pre-tested schedule was used to collect information from the study participants. Study population was described using proportion, mean and standard deviation. Data was analysed using chi-square test and Fisher exact test.

\section{RESULTS}

A total of 354 study participants with a mean age of $23.34 \pm 3.8$ years participated in the current study in which $63.84 \%$ of the study participants had initiated breastfeeding within 1 hour of birth. Among the factors assessed statistically significant association was found with socioeconomic class $(\mathrm{p}=0.006)$ and place of delivery $(\mathrm{p}=0.003)$.

\section{CONCLUSION}

From the present study, it was observed that the early initiation of breastfeeding was either comparable or well above the studies conducted in various study areas in our country. To further improve the breastfeeding practices, counselling on proper breastfeeding practices should be provided to all the pregnant and lactating women during the antenatal visits, postnatal visits and immunisation sessions.

\section{KEYWORDS}

Early Initiation, Breastfeeding, Neonatal Mortality, Multistage Sampling, Counselling, Prevalence.

HOW TO CITE THIS ARTICLE: Sarmah RK, Sarma R, Saikia H. Factors associated with early initiation of breastfeeding among mothers of Dibrugarh district, Assam- A community-based cross-sectional study. J. Evolution Med. Dent. Sci. 2017;6(69):48994902, DOI: $10.14260 / \mathrm{Jemds} / 2017 / 1062$

\begin{abstract}
BACKGROUND
Early or timely initiation of breastfeeding, specifically within 1 hour of birth, refers to the best practice recommended by the World Health Organization (WHO). ${ }^{1}$ Early initiation of breastfeeding is extremely important for establishing successful lactation as well as for providing 'colostrum' to the baby. ${ }^{2}$ There is growing evidence of the significant impact of early initiation of breastfeeding, preferably within the first hour after birth, on reducing overall neonatal mortality. ${ }^{3}$ NFHS-4 Dibrugarh reported that the prevalence of initiation of breastfeeding was $66.9 \%$ among the mothers having children under 3 years of age. ${ }^{4}$ India's current IMR and NMR is 40 and 28 respectively and in Assam the current IMR and
\end{abstract}

Financial or Other, Competing Interest: None.

Submission 30-06-2017, Peer Review 15-08-2017,

Acceptance 21-08-2017, Published 28-08-2017.

Corresponding Author:

Dr. Rahul Kumar Sarmah,

C/o. Mr. Manoj Kumar Sarmah,

Dolphin Enclave, Block-B,

Near Dispur G. N. R. C. Hospital,

Assam-781006.

E-mail: drrahul.sarmah100@gmail.com

DOI: $10.14260 /$ jemds/2017/1062

\section{(c) (i) $\ominus$}

NMR is 54 and $27.5^{5}$ India has missed the target set by MDG. One of the major underlying causes of infant and neonatal mortality might be the inadequate or discriminatory care practices prevalent in the society. The key care practices during infancy which has long-term implications in survival of the infant are early initiation of breastfeeding, exclusive breastfeeding, timely and adequate complementary feeding. ${ }^{6}$ Appropriate breastfeeding practice means early initiation of breastfeeding within 1 hour of delivery, no prelacteal feeding, no discarding of colostrum and giving only breast milk till 6 months of age. A mother needs knowledge regarding these in order to practice them and that depends on the mother's education, her socioeconomic status, her access to information regarding breastfeeding, taboos, and so on. ${ }^{7}$ Optimal breastfeeding of infants under two years of age has the greatest potential impact on child survival of all preventive interventions, with the potential to prevent over 800,000 deaths (13 percent of all death) in children under five in the developing world. ${ }^{8}$

As the studies on the early initiation of breastfeeding and its determinant are very few in number, this present study has been undertaken with the objective of to study the current prevalence of early initiation of breastfeeding in 
Dibrugarh district, Assam, India and to assess the various factors influencing early initiation of breastfeeding.

\section{MATERIALS AND METHODS}

The present study was a community-based cross-sectional study conducted over a period of one year from June 2015 to May 2016. Dibrugarh district has 6 health blocks and out of these 6 health blocks, Lahoal block was selected randomly for the present study. There were a total of 32 subcentres in Lahoal block. Considering the prevalence of early initiation of breastfeeding as $66.9 \%$ in Dibrugarh District (NFHS 4) and taking $5 \%$ as absolute precision at $95 \%$ confidence interval, the sample size of 354 was calculated.

Sampling design used was multistage sampling technique. Out of the total 32 subcentres of Lahoal block, 24 subcentres were selected randomly and the required sample size of 354 mothers were allocated proportionately among the 24 subcentres.

In each of the subcentre, the first house was selected randomly, thereafter consecutive houses were visited for the presence of the study participants until the required number of study subjects in each subcentre was obtained. The same procedure was repeated in all the subcentres until the required sample size was achieved.

Prior to the commencement of the field work, the study participants were carefully briefed regarding the purpose of the study so as to obtain their full co-operation for the study. The study participants were interviewed by house-to-house visit. At every household, the presence of a mother having children up to one year of age was first ascertained. If a mother having children up to one year of age was present, she was included or excluded from the study based on the criteria given earlier. Data was collected by interviewing the study participants using a pre-designed and pre-tested schedule.

Ethical clearance was obtained from the Institutional Ethics Committee (H) of Assam Medical College and Hospital, Dibrugarh. Written informed consent was obtained from the study participants prior to the onset of the study.

All the Mothers aged 15-49 years having children up to one year of age residing in the study area were included in the study. However, mothers who were not willing to give consent were excluded. The study population was described by using proportion, mean and standard deviation. Data was analysed using Chi-square test and Fisher's exact test.

\section{RESULTS}

\section{Sociodemographic Profile}

Majority $(56.50 \%)$ of the study participants were in the age group of 20-24 years with mean age of $23.34 \pm 3.8$ years. Out of the 354 study participants, most (49.44\%) of the participants belonged to the other backward castes. The literacy rate was $72.03 \%$ among mothers. Predominant proportion of the study participants belonged to the rural areas $(76.84 \%)$, and were from Joint family $(66.67 \%)$ and most (35.88\%) of the participants belonged to socioeconomic class III according to the Modified B.G. Prasad Classification [Table 1].

\section{Place of Delivery}

A total of 303 (85.59\%) of the study participants delivered in the hospital [Table 2].

\section{Prevalence of Early Initiation of Breastfeeding}

From 354 study participants, $63.84 \%$ of the study participants had initiated breastfeeding within 1 hour of birth [Table 3].

\section{Early Initiation of Breastfeeding and its Factors}

From our present study, it was observed that $79.31 \%$ of study participants in the age group of 30-39 years had early initiation of breastfeeding which was higher than the rest of the age groups. Early initiation of breastfeeding was more (76.09\%) among mothers who were educated up to higher secondary and above. $67.07 \%$ of the study participants among urban area and $62.87 \%$ in rural areas had initiated breastfeeding within 1 hour of birth. The prevalence of early initiation was $67.80 \%$ in nuclear family and $61.80 \%$ among joint family. Early initiation of breastfeeding was more $(75 \%)$ in the socioeconomic class I than among other socioeconomic classes. Finally, $67 \%$ of the study participants who delivered in the hospital had an early initiation of breastfeeding which was higher than the study participants delivered in their home. Among the factors assessed, association was found to be statistically significant with socioeconomic status and place of delivery $(\mathrm{p}<0.05)$ [Table 4].

\begin{tabular}{|c|c|c|c|}
\hline \multicolumn{2}{|c|}{ Variable } & Frequency & $\%$ \\
\hline \multirow{3}{*}{$\begin{array}{l}\text { Age of women } \\
\text { (years) }\end{array}$} & $15-19$ & 31 & 8.76 \\
\hline & $20-29$ & 294 & 83.05 \\
\hline & $30-39$ & 29 & 8.19 \\
\hline \multirow{4}{*}{$\begin{array}{l}\text { Educational } \\
\text { Qualification }\end{array}$} & Below Primary & 109 & 30.79 \\
\hline & $\begin{array}{l}\text { Primary \& middle } \\
\text { school }\end{array}$ & 118 & 33.33 \\
\hline & High School & 81 & 22.88 \\
\hline & $\begin{array}{l}\text { Higher sec. \& } \\
\text { above }\end{array}$ & 46 & 13.00 \\
\hline \multirow{2}{*}{$\begin{array}{l}\text { Place of } \\
\text { residence }\end{array}$} & Rural & 272 & 76.84 \\
\hline & Urban & 82 & 23.16 \\
\hline \multirow{2}{*}{$\begin{array}{l}\text { Type of } \\
\text { family }\end{array}$} & Nuclear & 118 & 33.33 \\
\hline & Joint & 236 & 66.67 \\
\hline \multirow{2}{*}{ Caste } & General & 126 & 35.59 \\
\hline & Other castes & 228 & 64.41 \\
\hline \multirow{5}{*}{$\begin{array}{l}\text { Socio- } \\
\text { economic } \\
\text { status }\end{array}$} & Class I & 28 & 7.91 \\
\hline & Class II & 43 & 12.15 \\
\hline & Class III & 127 & 35.88 \\
\hline & Class IV & 106 & 29.94 \\
\hline & Class V & 50 & 14.12 \\
\hline & $\begin{array}{l}\text { Sociodemogra } \\
\text { of the Study } P\end{array}$ & $\begin{array}{l}\text { aracte } \\
\text { ants }\end{array}$ & \\
\hline
\end{tabular}

\begin{tabular}{|c|c|c|}
\hline Place of Delivery & Frequency & Percentage \\
\hline Hospital & 303 & 85.59 \\
\hline Home & 51 & 14.41 \\
\hline Total & 354 & 100.00 \\
\hline \multicolumn{2}{|c|}{ Table 2. Study Participants According to } \\
the Place of Delivery \\
\hline
\end{tabular}

\begin{tabular}{|c|c|c|}
\hline $\begin{array}{c}\text { Initiation of } \\
\text { Breastfeeding }\end{array}$ & Frequency & Percentage \\
\hline$\leq 1$ hour & 226 & $63.84 \%$ \\
\hline$>1$ hour & 128 & $36.16 \%$ \\
\hline Total & 354 & 100.00 \\
\hline
\end{tabular}




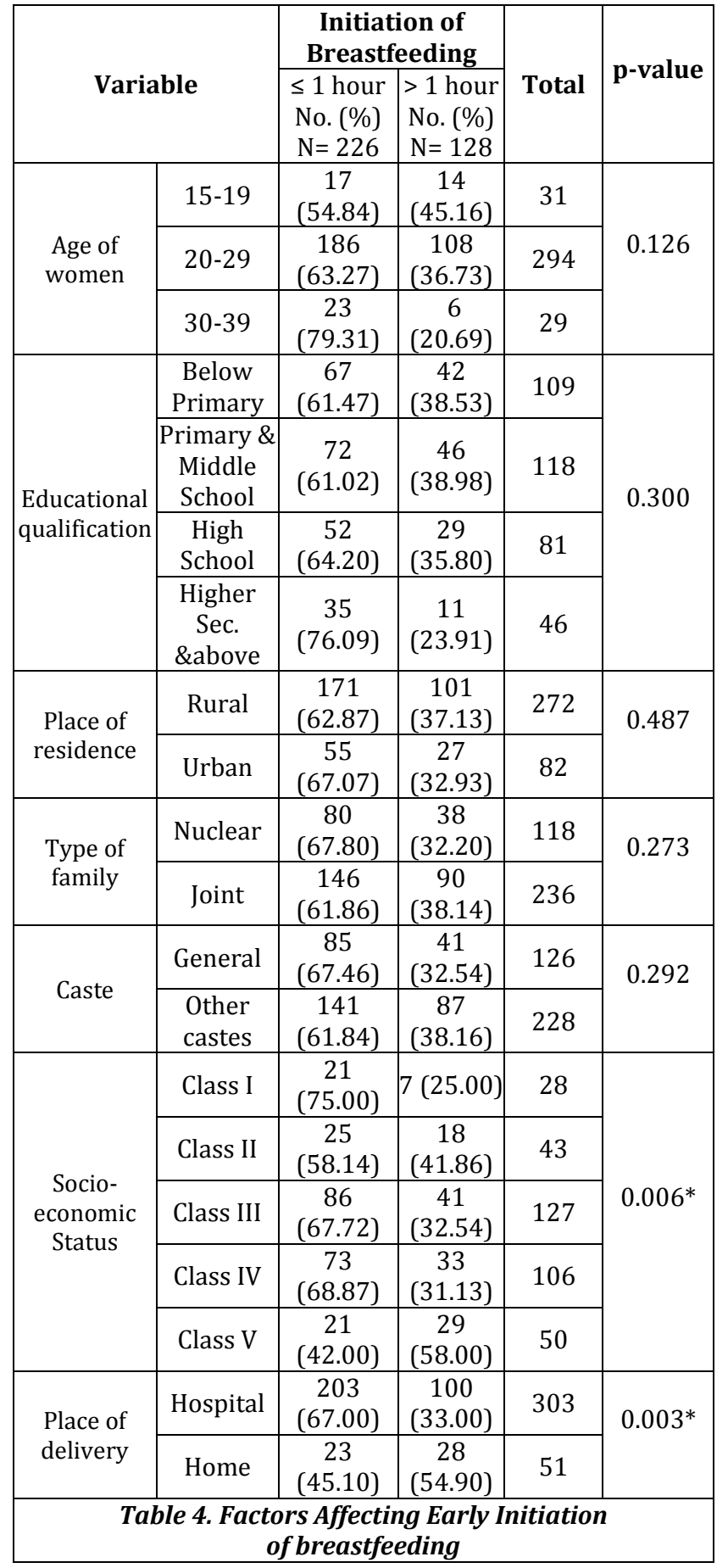

*Significant at $1 \%$ level of significance.

\section{DISCUSSION}

In our present study, the prevalence of early initiation of breastfeeding (63.84\%) was comparable to the study conducted by Kalita D et $\mathrm{al}^{6}$ in Kamrup district of Assam and NFHS-4 Dibrugarh, ${ }^{4}$ but it is higher as compared to the study conducted by other studies. $9,10,11,12$ In our present study, early initiation of breastfeeding increases with increasing maternal age which is similar to the results obtained by Sandor $\mathrm{M}$ et al $^{13}$ from NFHS-3 data and Berde AS et al. ${ }^{14}$ However, a similar study conducted by Sharma A et al ${ }^{12}$ observed that $41 \%$ of the mothers in the age group of $15-24$ years started early initiation of breastfeeding as compared to $27 \%$ in the age group of 25-34 years. In our present study, early initiation was more prevalent (76.09\%) in mothers who had educational level of higher secondary and above than those of other groups which is similar to the study conducted by Sharma A et al, ${ }^{9}$ Sandor $\mathrm{M}$ et al ${ }^{13}$ and also by Liben ML et al. ${ }^{15}$ As observed in this present study, $67.07 \%$ of the urban mothers had early initiation of breastfeeding while $62.87 \%$ of the rural mothers had early initiation of breastfeeding which is similar to the results obtained by Yadav YS et al ${ }^{16}$ and Lubala TS et $\mathrm{al}^{17}$ in their study. In another study conducted by Ashwini $\mathrm{S}$ et al, ${ }^{7}$ prevalence of early initiation of breastfeeding was almost comparable in urban and rural areas. The study observed that early initiation of breastfeeding was more $(67.80 \%)$ in the mothers who belonged to nuclear family than the joint family $(61.86 \%)$ which is different from the study conducted by Sharma A et al. ${ }^{9}$ Percentage of the women practising early initiation was found to be $67.46 \%$ among mothers from general caste and $61.84 \%$ in mothers among other castes in this study which is comparable with the findings of Sandor M et al. ${ }^{13}$ Our study also observed that the early initiation was higher (75\%) among mothers who belonged to socioeconomic class I which is similar to the results obtained by Kakati $\mathrm{R}$ et $\mathrm{al}^{10}$ and Sandor $\mathrm{M}$ et al. ${ }^{13}$ Early initiation of the breastfeeding was higher in mothers who delivered in hospital than those who delivered at home which is similar to the findings reported by Sharma $\mathrm{A}$ et $\mathrm{al}^{9}$ and Sandor M et al. ${ }^{13}$

\section{CONCLUSION}

The present study assessed the prevalence of early initiation of breastfeeding which is either comparable or well above the studies conducted in various parts of our country. To further improve the various breastfeeding practices, proper breastfeeding practices counselling should be provided to all the pregnant and lactating women during the antenatal visits, postnatal visits and in immunisation sessions. This needs to be accompanied by frequent home visits at regular intervals and also to supervise and demonstrate the correct technique of breastfeeding to the mothers. There is a need to empower existing health care workers like Auxiliary Nurses and Midwives (ANMs) and Anganwadi Workers (AWWs) to become efficient breastfeeding counsellors through various training sessions. Breastfeeding counsellor would be a better option in hospitals.

\section{REFERENCES}

[1] Sharma IK, Byrne A. Early initiation of breastfeeding: a systematic literature review of factors and barriers in South Asia. International Breastfeeding Journal 2016;11:17.

[2] 'National Guidelines on Infant and Young Child Feeding', Food and Nutrition Board, Department of Women and Child Development, Ministry of Human Resource Development, Government of India, 2004.

[3] Berkat S, Sutan R. The effect of early initiation of breastfeeding on neonatal mortality among low birth weight in Aceh province, Indonesia: an unmatched case control study. Advances in Epidemiology 2014;Article ID 358692:pp 7.

[4] National Family Health Survey NFHS 4 India 2015-16, International Institute of population sciences, Mumbai, India. 
[5] Govt. of India. Sample registration system statistical report 2014, Office of the Registrar General and Census Commissioner of India, Ministry of Home Affairs, New Delhi, 2015.

[6] Kalita D, Borah M. Current practices on infant feeding in rural areas of Assam, India: a community-based cross sectional study. Int J Community Med Public Health 2016;3(6):1454-60.

[7] Ashwini S, Katti SM, Mallapur MD. Comparison of breastfeeding practices among urban and rural mothers: a cross-sectional study. Int J Med Public Health 2014;4(1):120-4.

[8] United Nation Children's Fund (UNICEF). Nutrition 2015. [cited 2017 May 30]. Available from: http://www.unicef.org/nutrition/index.

[9] Sharma A, Thakur PS, Tiwari R, et al. Factors associated with early initiation of breastfeeding among mothers of tribal area of Madhya Pradesh, India: a community-based cross sectional study. International Journal of Community Medicine and Public Health 2016;3(1):194-9.

[10] Kakati R, Rahman SJ. Timely initiation of breastfeeding and its determinants among mothers in rural areas of Kamrup District, Assam, India. Indian Journal of Applied Research 2016;6(8):49-53.

[11] Kumari SM, Muralidhar K. A study on breastfeeding practices in rural and urban Warangal, Andhra Pradesh. MRIMS Journal of Health Sciences 2015;3(1):73-5.
[12] Noor S, Rajesh AH, Babu GK. A study on breastfeeding practices among mothers of Urban slums of Rourkela. IOSR Journal of Dental and Medical Sciences 2015;14(5):77-80.

[13] Sandor M, Dalal K. Influencing factors on time of breastfeeding initiation among a national representative sample of women in India. Health 2013;5(12):2169-80.

[14] Berde AS, Yalcin SS. Determinants of early initiation of breastfeeding in Nigeria: a population-based study using the 2013 demographic and health survey data. BMC Pregnancy Childbirth 2016;16:32.

[15] Liben Ml, Yesuf EM. Determinants of early initiation of breastfeeding in Amibara district, North-eastern Ethiopia: a community-based cross-sectional study. International Breastfeeding Journal 2016;11(7).

[16] Yadav YS, Yadav S, Rathi SS, et al. Comparison of infant feeding practices among rural and urban mothers: an observational study. Int J Med Res Rev 2015;3(6):54753.

[17] Lubala TK, Mukuku O, Mutambo AM, et al. Infant feeding practices in urban and rural southern Katanga communities in democratic republic of Congo. The Journal of Medical Research 2016;2(3):65-70. 